\title{
A SURVEY OF MENTAL HOSPITALS AND MENTAL DEFICIENCY INSTITUTIONS IN THE BIRMINGHAM REGION
}

\author{
1. MENTAL HOSPITALS
}

BY

\author{
K. W. CROSS \\ From the Department of Medical Statistics, University of Birmingham, and Birmingham Regional Hospital Board
}

\section{INTRODUCTION}

The problem of providing adequate care and treatment for patients suffering from mental disorder has become more acute in recent years for many reasons, not least amongst them being the increased numbers and longevity of the population in conjunction with their greater willingness to seek early advice and treatment. As a result, mental hospitals are faced with the dilemma of increasing their admission rates and at the same time continuing to look after an increasing proportion of long-stay chronic patients who are living longer.

Associated with an increasing psychiatric awareness in the general population, are other social agencies contributing to the increased numbers of patients, such as the unwillingness of families to accept responsibility, and provide a home, for parents too aged or too infirm to look after themselves. All too often therefore, a patient, who is otherwise fit for discharge, remains in hospital because he has nowhere else to go.

The problem is a national one. Even before the last war there was a considerable shortage of beds for mental illness, and the inadequate provision of accommodation in the past has been accentuated by apparent deficiencies in planning since the 1946 Act. In August, 1951, regional boards were told by the Ministry of Health that their planning on the mental side was quite incommensurate with the needs of the situation. Furthermore, the problem of mental hospital accommodation is qualitative as well as quantitative. Most accommodation is extremely out-of-date; only a handful of mental hospitals have been built since 1918, and the majority were in existence before the Lunacy Act of 1890 .

Coincident with greater overcrowding at most hospitals, the general shortage of nursing staff has been aggravated by the loss of trained and experienced personnel; and the continuance of the service even at its present level is made possible only by employing less trained personnel and by using many part-time staff. Future staffing problems will be increased by falling recruitment and the high wastage rate of student mental nurses. The former is closely linked with the present financial situation, in that the hospital service cannot compete with industry in respect of salaries and hours of duty. The latter is largely due to overcrowding, and the vicious circle must be broken before improvements can be expected. The consequences of employing larger numbers of domestic staff call for special consideration, since this would lessen the wastage from employment of nursing staff on non-nursing duties.

\section{Aims of The Survey}

In view of the large number of patients involved, the degree of overcrowding, and the apparent shortages of many types of staff, it was decided that an examination should be made of the type of case at present being cared for and treated in the mental hospitals of the Birmingham Region, with special reference to the most effective utilization of skilled personnel.

By no means all the relevant information for such an investigation in its entirety is readily available from the existing records; it will be possible to give a complete picture embodying all types of information only by modifying the design of individual case records. This survey is therefore concerned with those aspects which could be adequately covered by the use of forms designed for completion at source and without recourse to case records. Thus the immediate aims of the survey include:

(i) an evaluation of the type of case on each ward with respect to certain well-defined factors;

(ii) a review of the ward-by-ward disposition of nursing and domestic staff and accommodation available;

(iii) a review of medical and various other types of staff available at the date of the survey;

(iv) an assessment of staff accommodation available;

(v) a determination of the present level of operation of psychiatric out-patient clinics. 
One type of relevant information calls for special comment in this context because the unavoidable lack of it adds great difficulty to the task of assessing the shortage of qualified personnel. Whether mental patients as a whole make greater or less demands on qualified personnel than other hospitalized cases treated likewise as a whole can be satisfactorily answered only if it is possible to classify both major categories with the same measure of precision. There is in fact no uniform system of diagnostic specification for mental disorders in the country as a whole or the region in particular, nor would it necessarily add much to our knowledge if there were; and the deliberations of the Inter-Services Committee on psychiatric nomenclature during the late war does not encourage the hope of early agreement with respect to terminology, still less with respect to diagnostic classification. Thus the current usage of terms less than ever endorses a clear-cut demarcation between the dangerously sick and those suffering from milder disorders, or of the latter from persons whom we may deem to be normal; and the difficulty of budgeting personnel requirements $v$ is $a$ vis case severity is not one which any immediate proposals for improved documentation, unless very drastic, would remedy. Drastic improvements are scarcely practicable in the light of shortages of personnel for documentation in institutions other than general hospitals.

One omission calls for special comment. In the past, and to a varying extent in different regions, general hospitals may have set apart wards for mental patients. In the Birmingham Region this is a rarity, the only notable exception to the segregation of mental patients being the wards provided at Stoke City General Hospital. Thus any error resulting from the exclusion of patients in general hospitals is trivial. Needless to say, a thorough analysis of the work of the out-patient clinics, especially if accompanied by a follow-up, would be invaluable. It is therefore regrettable that it is possible to record so little about the work of the out-patient departments at this stage, for the reason that records kept in the Region to date are of doubtful value.

\section{Accommodation Available for Mental Patients in the Birmingham Region}

In this Region, which has a population of $4,444,000$, 13,200 beds are allocated to mental disease in thirteen hospitals; accommodation is therefore available at the rate of 3,000 beds per million population.* But this level has been made possible only by the provision of a considerable number

\footnotetext{
${ }^{*}$ The national rate is 3,400 beds per million population.
}

of beds in addition to the statutory number for which the hospitals were designed.

An examination of ward returns designed for collection of data relevant to $2(i)$ and 2 (ii) above reveals considerable inter-ward differences in degrees of overcrowding, defined with respect to statutory accommodation* as base. At most hospitals the admission unit is not overcrowded and hence the lower limit of the range of percentage overcrowding is zero in each case. We here consider only the overcrowding at night, this being the more important, and Table I shows for each hospital, for males and females respectively, the number of wards which are overcrowded within certain ranges and the average overcrowding for each hospital as a whole.

Male Side.-Only two hospitals have an appreciable number of wards not overcrowded. Otherwise, at least five wards at any one hospital are overcrowded. In the region as a whole, the proportion of such wards is 71 per cent. Excluding the two hospitals mentioned above, the proportion is 80 per cent. The number of wards overcrowded by less than 10 per cent. is very small, and no less than 35.7 per cent. are overcrowded by 25 per cent. or more. At five hospitals more than half the wards are overcrowded by 25 per cent. or more, and at the Central Hospital four of the eleven wards are overcrowded by 50 per cent. or more.

Female Side.-Only 20 per cent. of the wards are not overcrowded, and at three hospitals all wards are overcrowded to some degree. There appear to be only two hospitals with a reasonable proportion of wards not overcrowded at night. The largest number of female wards appears in the category 25-49.9 per cent. overcrowded. In fact, half the wards in the Region are overcrowded at night by 25 per cent. or more, and almost one-fifth by 50 per cent. or more. There is only one exception to the rule that there is greater overcrowding in female than in male wards.

\section{Analysis of Patients in Residence}

We may now proceed to examine data referable to the patients resident in the mental hospitals of the Region at the time of the survey. Relevant information was obtained ward by ward and summarized by

*The assessment of day and night accommodation in mental hospitals is based on prescribed space allowances as given on the Ministry of Health Accommodation Return (Form M.H.S. 3). The statutory accommodation by day is calculated on a minimum area of floor space of about 40 sq. ft. per patient, although a minimum area per patient is given for each of six classes of patients. The statutory sleeping accommodation is calculated, according to the classification of the ward, either $(a)$ on beds in position spaced according to prescribed distances between bed centres (about $5 \mathrm{ft}$.
on the average), or $(b)$ on the minimum area of floor space (about on the average), or (b) on the minimum area of flo
50 sq. $\mathrm{ft}$. per patient), the smaller figure being given. 
TABLE I

SLEEPING ACCOMMODATION FOR MENTAL PATIENTS IN THE BIRMINGHAM REGION

\begin{tabular}{|c|c|c|c|c|c|c|c|c|c|c|}
\hline & & Statutory & & Per cent & & & & Wards Ove & rowded by & \\
\hline Name of Hospi & ital & $\begin{array}{c}\text { Accommo- } \\
\text { dation }\end{array}$ & $\begin{array}{c}\text { of } \\
\text { Patients }\end{array}$ & $\begin{array}{l}\text { Over- } \\
\text { crowding }\end{array}$ & $\begin{array}{l}\text { Wards } \\
\text { Open }\end{array}$ & $\begin{array}{c}\text { Over- } \\
\text { crowded }\end{array}$ & $\underset{\text { per cent. }}{<10}$ & $\begin{array}{l}10-24 \cdot 9 \\
\text { per cent. }\end{array}$ & $\begin{array}{l}25-49 \cdot 9 \\
\text { per cent. }\end{array}$ & $\begin{array}{l}50 \text { per } \\
\text { cent. and } \\
\text { over }\end{array}$ \\
\hline $\begin{array}{l}\text { MALES } \\
\text { St. George's } \\
\text { St. Edward's } \\
\text { Winson Green } \\
\text { Rubery Hill } \\
\text { Hollymoor } \\
\text { Highcroft Hall } \\
\text { Burghill } \\
\text { Powick . } \\
\text { Barnsley Hall } \\
\text { St. Matthew's } \\
\text { Central . . } \\
\text { Shelton . . }\end{array}$ & $\begin{array}{l}\ldots \\
\cdots \\
\cdots \\
\cdots \\
\cdots \\
\cdots \\
\cdots \\
\cdots\end{array}$ & $\begin{array}{l}433 \\
569 \\
488 \\
353 \\
332 \\
500 \\
232 \\
377 \\
276 \\
483 \\
466 \\
364\end{array}$ & $\begin{array}{l}495 \\
682 \\
560 \\
329 \\
297 \\
461 \\
232 \\
440 \\
328 \\
532 \\
593 \\
461\end{array}$ & $\begin{array}{c}14.3 \\
19.9 \\
12.9 \\
= \\
= \\
0.0 \\
16.7 \\
18.8 \\
10.1 \\
27.3 \\
26.6\end{array}$ & $\begin{array}{c}13 \\
13 \\
11 \\
7 \\
9 \\
9 \\
7 \\
8 \\
7 \\
10^{*} \\
11 \\
7\end{array}$ & $\begin{array}{r}10 \\
10 \\
8 \\
6 \\
3 \\
2 \\
5 \\
6 \\
6 \\
7 \\
9 \\
7\end{array}$ & $\begin{array}{l}\frac{1}{2} \\
\frac{1}{3} \\
\frac{1}{1} \\
\frac{1}{1}\end{array}$ & $\begin{array}{l}2 \\
3 \\
4 \\
1 \\
2 \\
2 \\
2 \\
3 \\
2 \\
3 \\
2 \\
1\end{array}$ & $\begin{array}{l}4 \\
6 \\
2 \\
1 \\
- \\
3 \\
4 \\
3 \\
3 \\
5\end{array}$ & $\begin{array}{l}3 \\
\frac{1}{1} \\
= \\
= \\
= \\
\overline{4}\end{array}$ \\
\hline All Hospitals & . & 4,873 & 5,410 & $11 \cdot 0$ & 112 & 79 & 12 & 27 & 31 & 9 \\
\hline $\begin{array}{l}\text { FEMALES } \\
\text { St. George's } \\
\text { St. Edward's } \\
\text { Winson Green } \\
\text { Rubery Hill } \\
\text { Hollymoor } \\
\text { Highcroft Hall } \\
\text { Burghill } \\
\text { Holme Lacy } \\
\text { Powick } \\
\text { Barnsley Hall } \\
\text { St. Matthew's } \\
\text { Central .. } \\
\text { Shelton .. }\end{array}$ & 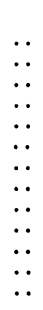 & $\begin{array}{l}531 \\
545 \\
592 \\
439 \\
307 \\
727 \\
270 \\
106 \\
482 \\
325 \\
534 \\
532 \\
506\end{array}$ & $\begin{array}{l}705 \\
702 \\
805 \\
584 \\
336 \\
708 \\
298 \\
73 \\
575 \\
399 \\
644 \\
772 \\
561\end{array}$ & $\begin{array}{l}32 \cdot 8 \\
28 \cdot 8 \\
36 \cdot 0 \\
33 \cdot 0 \\
9 \cdot 4 \\
\overline{10 \cdot 4} \\
\overline{19 \cdot 3} \\
22 \cdot 8 \\
20 \cdot 6 \\
45 \cdot 1 \\
10 \cdot 9\end{array}$ & $\begin{array}{r}13 \\
13 \\
14 \\
11 \\
8 \\
14 \\
8 \\
3 \\
9 \\
8 \\
18 \\
14 \\
9\end{array}$ & $\begin{array}{r}11 \\
13 \\
12 \\
11 \\
4 \\
9 \\
5 \\
8 \\
8 \\
14 \\
12 \\
7\end{array}$ & $\begin{array}{l}\frac{1}{1} \\
\frac{2}{3} \\
\frac{1}{1} \\
\frac{4}{2} \\
\frac{4}{4}\end{array}$ & $\begin{array}{l}\overline{4} \\
2 \\
2 \\
1 \\
2 \\
1 \\
5 \\
1 \\
7 \\
1\end{array}$ & $\begin{array}{l}5 \\
4 \\
6 \\
5 \\
3 \\
3 \\
1 \\
2 \\
2 \\
4 \\
7 \\
2\end{array}$ & $\begin{array}{l}5 \\
5 \\
3 \\
2 \\
1 \\
\frac{1}{1} \\
1 \\
1 \\
5 \\
-\end{array}$ \\
\hline All Hospitals & .. & 5,896 & 7,162 & $21 \cdot 5$ & 142 & 114 & 18 & 26 & 44 & 26 \\
\hline
\end{tabular}

*Excluding eight dormitories which together are overcrowded by $11 \cdot 3$ per cent.

hospital for males and females separately. In what follows a regional summary is given for each of a number of items, together with the range of interhospital variation where appropriate.

It should be mentioned at the outset that the in-patient populations of two hospitals are exceptional in many aspects. One was a Poor-Law institution before the "Appointed Day"; here most patients are still classified as voluntary cases, and a high proportion of in-patients are aged 65 years and over. The other is small in size and the patients in residence are mostly female voluntary cases over
65 years of age. In view of these peculiarities these hospitals may not always be mentioned in subsequent reference to extremes of the following distributions.

Age Distribution.-The number of patients falling into each of three age groups is given in Table II, which also shows the proportions of the total inpatient population classified as Voluntary, Certified, etc., for each age group specified. The Table shows that 0.4 per cent. of the male and 0.6 per cent. of the female patients in residence were under 16 years of age. St. Edward's Hospital and Highcroft Hall Hospital

TABLE II

AGE AND CLASSIFICATION (ACCORDING TO SECTION OF L.M.T.A.) OF PATIENTS

\begin{tabular}{|c|c|c|c|c|c|c|c|c|c|c|}
\hline \multirow{2}{*}{ Sex } & \multirow{2}{*}{\multicolumn{2}{|c|}{$\begin{array}{l}\text { Section of } \\
\text { L.M.T.A. }\end{array}$}} & \multicolumn{2}{|c|}{ Under 16 Yrs } & \multicolumn{2}{|c|}{ 16-64 Yrs } & \multicolumn{2}{|c|}{65 and Over } & \multicolumn{2}{|c|}{ All Age Groups } \\
\hline & & & No. & $\begin{array}{l}\text { Per cent. of } \\
\text { All Patients }\end{array}$ & No. & $\begin{array}{l}\text { Per cent. of } \\
\text { All Patients }\end{array}$ & No. & $\begin{array}{l}\text { Per cent. of } \\
\text { All Patients }\end{array}$ & No. & $\begin{array}{l}\text { Per cent. of } \\
\text { All Patients }\end{array}$ \\
\hline \multirow[t]{2}{*}{ Male } & $\begin{array}{l}\text { Voluntary } \\
\text { Certified .. } \\
\text { Other .. }\end{array}$ & $\begin{array}{l}\ddot{*} \\
\ddot{*}\end{array}$ & $\frac{1}{23}$ & $\begin{array}{l}0.0 \\
0.4 \\
-\end{array}$ & $\begin{array}{r}824 \\
3,376 \\
15\end{array}$ & $\begin{array}{r}15 \cdot 2 \\
62 \cdot 4 \\
0 \cdot 3\end{array}$ & $\begin{array}{r}259 \\
908 \\
4\end{array}$ & $\begin{array}{r}4 \cdot 8 \\
16 \cdot 8 \\
0 \cdot 1\end{array}$ & $\begin{array}{r}1,084 \\
4,307 \\
19\end{array}$ & $\begin{array}{r}20.0 \\
79.6 \\
0.4\end{array}$ \\
\hline & Totals & $\cdots$ & 24 & 0.4 & 4,215 & $77 \cdot 9$ & 1,171 & $21 \cdot 7$ & 5,410 & $100 \cdot 0$ \\
\hline \multirow[t]{2}{*}{ Female } & $\begin{array}{l}\text { Voluntary } \\
\text { Certified .. } \\
\text { Other .. }\end{array}$ & $\ddot{\ddot{*}}$ & $\begin{array}{r}5 \\
21 \\
18\end{array}$ & $\begin{array}{l}0 \cdot 1 \\
0 \cdot 3 \\
0 \cdot 2\end{array}$ & $\begin{array}{r}898 \\
3,739 \\
16\end{array}$ & $\begin{array}{r}12 \cdot 5 \\
52 \cdot 2 \\
0 \cdot 2\end{array}$ & $\begin{array}{r}538 \\
1,916 \\
11\end{array}$ & $\begin{array}{r}7 \cdot 5 \\
26 \cdot 7 \\
0 \cdot 2\end{array}$ & $\begin{array}{r}1,441 \\
5,676 \\
45\end{array}$ & $\begin{array}{r}20 \cdot 1 \\
79 \cdot 2 \\
0.6\end{array}$ \\
\hline & Totals & $\cdots$ & 44 & $0 \cdot 6$ & 4,653 & $64 \cdot 9$ & 2,465 & $34 \cdot 4$ & 7,162 & $100 \cdot 0$ \\
\hline
\end{tabular}


are the only two with a not insignificant number of patients in this age group. A far higher proportion of males than females falls within the age-group 16 to 64 years, and this holds for each hospital. On the male side, there are abnormally large proportions (over 30 per cent.) of patients aged 65 years and over at two hospitals, and the range of variation about the regional average of 21.7 per cent. is from $14 \cdot 7$ to 32.7 per cent. On the female side, more than onethird (34.4 per cent.) of all patients are aged 65 years and over, and for individual hospitals this proportion varies from $25 \cdot 7$ to $39 \cdot 3$ per cent. The age-composition of the in-patient population will be discussed in greater detail in Section 7, when the consequences of current trends will be considered.

Classification of Patient Population according to Section of Lunacy and Mental Treatment Act.-This also merits comment. In Table II patients not classified as voluntary or certified (i.e. temporary patients, "place-of-safety" cases, etc.) have been grouped together in view of the very small numbers involved. The proportions of voluntary and certified patients in the Region as a whole are almost identical for males and females, and exactly one-fifth of all patients in residence are voluntary patients. With respect to these proportions, however, there are considerable variations between hospitals. On the male side, most hospitals have less than 20 per cent. voluntary patients whilst Highcroft Hall Hospital and Central Hospital far exceed this value. At one hospital (Barnsley Hall) the proportion of certified patients is as high as 91.4 per cent. and at four other hospitals more than 85 per cent. are certified. On the female side, the highest proportion of certified female patients is 92.8 per cent. (Rubery Hill), and at four other hospitals more than 85 per cent. are certified.

By means of Table II it is possible to relate age to classification. The proportion of voluntary cases (and hence of certified cases) for all adults is, it appears, the same as for each age group, taking into account the relative proportions of patients within those age groups. Thus there is no association between age and classification in the Region as a whole for either sex. We find, however, that in a few individual hospitals there are outstandingly high or low proportions of certified patients in one or other of the age groups.

Length of Stay.-This is also a circumstance of considerable value when assessing the type of patient residing in a mental hospital. Of all patients in the Regional mental hospitals, 85 per cent. have been resident for a year or more. Since a patient who has been in hospital for such a period is unlikely to be discharged, this proportion is a rough measure of the magnitude of the chronic section of the in-patient population. There is little variation from hospital to hospital in respect of this proportion; the highest figure for both sexes is 91.5 per cent. (Winson Green) and the lowest figures are 78 and 69 per cent. on the male and female sides respectively.

A more conservative estimate of the proportion of chronic patients is given by the 70 and 72 per cent. of males and females respectively who have been in hospital more than 3 years. The high proportions (88 and 86 per cent. respectively) at Winson Green Hospital are again very outstanding. Excluding Hollymoor Hospital, which was re-opened in 1949, only two hospitals have proportions for either sex below 70 per cent. Slightly more than 61 per cent. of all patients have been in residence more than 5 years. Several hospitals have proportions above 70 per cent, and, with the exception of Hollymoor and Holme Lacy, more than half the patients in residence at each institution on the day of the survey had been in residence for longer than 5 years.

Mobility, Incontinence, and Assistance Required.In any assessment of the type of patient on a particular ward, with special reference to the disposition of trained personnel, it is necessary to make due allowance for the proportions of bedridden and incontinent patients, and for the degree of assistance required in feeding, bathing, etc. An examination of the number of patients on each ward requiring various forms of assistance showed that differing interpretations placed upon the recording of such data would not permit any comparison between hospitals, and the information recorded was deemed to be useful only for considering the disposition of personnel between wards at a particular hospital, as outlined in the classification of wards referred to below.

The regional summary for mobility and incontinence is given in Table III (opposite), which shows that about one-tenth of the male and one-eighth of the female patients are bedridden. There is less variation between hospitals in respect of the female proportions than of the male proportions, and at each hospital, with one exception, the proportion of female bedridden cases is higher than the corresponding male proportion. In the Region as a whole, almost 40 per cent. of the bedridden males and about 60 per cent. of the bedridden females require the bed-pan, and regardless of their mental states, such patients make considerable demands upon nursing strengths of hospitals. Many patients are, of course, both bedridden and incontinent, and hence require medical and skilled nursing supervision. Those that 
TABLE III

MOBILITY AND INCONTINENCE OF PATIENTS

\begin{tabular}{|c|c|c|c|c|c|}
\hline \multirow{2}{*}{\multicolumn{2}{|c|}{ Type of Patient }} & \multicolumn{2}{|c|}{ Males } & \multicolumn{2}{|c|}{ Females } \\
\hline & & Number & $\begin{array}{l}\text { Per cent. } \\
\text { of All } \\
\text { Patients }\end{array}$ & Number & $\begin{array}{l}\text { Per cent. } \\
\text { of All } \\
\text { Patients }\end{array}$ \\
\hline \multicolumn{2}{|c|}{$\begin{array}{l}\text { Bed-ridden } \\
\text { Requiring bedpan }\end{array}$} & $\begin{array}{l}514 \\
204\end{array}$ & $\begin{array}{l}9 \cdot 5 \\
3 \cdot 8\end{array}$ & $\begin{array}{l}917 \\
561\end{array}$ & $\begin{array}{r}12 \cdot 8 \\
7 \cdot 8\end{array}$ \\
\hline $\begin{array}{l}\text { Ambulant } \\
\text { Working }\end{array}$ & $\because$. & $\begin{array}{l}4,896 \\
2,859\end{array}$ & $\begin{array}{l}90.5 \\
52.8\end{array}$ & $\begin{array}{l}6,245 \\
2,723\end{array}$ & $\begin{array}{l}87 \cdot 2 \\
38 \cdot 0\end{array}$ \\
\hline All Patients & .. & 5,410 & $100 \cdot 0$ & 7,162 & $100 \cdot 0$ \\
\hline Incontinent & .. & 534 & $9 \cdot 9$ & 1,312 & $18 \cdot 3$ \\
\hline
\end{tabular}

are only incontinent may also require the service of a nurse or doctor at any time, irrespective of the degree of mental change, and the care of incontinent patients presents a greater problem on the female side than on the male at the large majority of hospitals.

Patient Labour.-Table III also shows that 53 per cent. of the male and 38 per cent. of the female patients in residence were working, although the proportion of workers of course varies considerably from hospital to hospital. Details of the place of employment of each patient were obtained, and it was found that 29 per cent. of the males and 23 per cent. of the females were working in their own wards. As would be expected, a much greater difference between the sexes in the proportions of patients working elsewhere was found, i.e. 24 per cent. for males and 15 per cent. for females. At most hospitals a greater proportion of the female patients work in the wards than elsewhere in the hospital. At several hospitals the converse is true on the male side.

To assess the value of patient labour wholly in terms of actual work done is misleading, since it takes no account of relief to members of the hospital staff, especially nursing staff, by keeping the patients occupied. Patient labour is also to some extent a form of occupational therapy. In considering such figures we must therefore take into account the proportions of patients at each hospital receiving prescribed occupational therapy in the more usual sense of the term. These proportions for the Region as a whole are 11 and 13 per cent. for males and females respectively, although again there are considerable inter-hospital differences. Since the same patients at some hospitals do routine work and also receive occupational therapy, proportions for workers and patients on occupational therapy are not additive.

There may well be, between hospitals, differences of interpretation with regard to what constitutes occupational therapy in contradistinction to work.
However, at nine of the twelve hospitals at least half of the male patients and at least one-third of the female patients in residence are kept occupied for some part of the day. Of these patients, those working elsewhere (i.e. other than on wards) probably contribute most to the services of the hospital, and patient man-hours calculated for such patients are more meaningful in terms of staff units than those relating to ward workers.

Special Mental Treatment.-The proportions of patients receiving occupational therapy have already been cited, and this form of treatment is the most common. Convulsion therapy is given at all hospitals, and some patients seen at the out-patient clinics become in-patients to receive it. Insulin shock therapy is given at most hospitals, although the number of patients receiving it on any given day is very small. Since the number of patients receiving any particular treatment will vary from week to week or month to month, it would be more instructive to cite an average over a sufficient period of time; but this was found to be impracticable. The results obtained from the ward returns pinpoint the treatment wards and hence assist in classifying the patients therein.

Classification of Wards by Type of Patient.-In the absence of information referable to the mental state of patients in residence, it is instructive to examine the ward returns with a view to classifying the wards at each hospital by type of patient against the background of various items considered above. It was found that wards may be classified into four major groups:

I Admission units and other wards with a large proportion of recent cases (over 50 per cent of the patients with a length of stay of less than 1 year);

II Wards with large proportions of bedridden cases;

III Wards with ambulant patients who for the most part are non-workers or working on their own wards;

IV Wards with a large proportion of patients working outside the wards.

The first group comprises wards housing patients with short durations of stay, and who are mostly voluntary patients under 65 years of age. At each hospital there is at least one ward for each sex in this group and such a ward is also conspicuous by the large proportion of patients receiving special mental treatment. The wards which fall into the second group are also clearly defined, since at each hospital bedridden cases, with very minor exceptions, appear to be confined to selected wards. A high proportion of these patients are 65 years of age or over and many require feeding and other assistance. There 
are more wards for this type of patient on the female side than on the male.

The remaining wards house patients who, with very minor exceptions, are all ambulant, and these may be separated into the third and fourth groups mentioned above by considering the proportion of patients working outside the wards. Broadly speaking, those patients employed outside the wards are likely to make less demands on the services of nursing personnel than other ambulant patients, and such a separation has been made with a view to what follows. The wards which fall into the fourth group are also distinguished by the small numbers of patients requiring assistance, and this group includes the non-observation wards. There are very few border-line cases, and the only wards excluded from the classification are isolation wards. These are small in number and size and do not merit further analysis. This classification will be used in the following section to review the availability of certain grades of staff at the time of the survey.

\section{StafF}

Medical Staff Employed.-Table IV shows the numbers of whole-time medically-qualified staff employed in the Region at the end of 1952 by grade, together with patient-staff ratios. At most hospitals there are two consultants and one S.H.M.O., and in addition one or two J.H.M.O.s. Few Senior Registrars are employed and half the hospitals have no medical staff of S.H.O. or H.O. grade. The Table shows that slightly more than half the total medical personnel are of consultant or S.H.M.O. grade and that a quarter are of J.H.M.O. grade. These figures reflect the difficulties in recruiting junior medical officers. There are 360 patients per consultant or S.H.M.O. in the Region as a whole, although, considering the inter-hospital variation, this ratio varies from 200 to 500 . Similarly, the range of variation about the regional average of 186 patients per doctor is from 100 to 240 .

It has been suggested that there should be one doctor for every 150 resident patients, and that where extra-mural duties are undertaken the staff should be larger (Blacker, 1946). Only two hospitals in this Region conform to this level of staffing, but such ratios take no cognizance of the type of patient.

It has not been possible to assess the time spent by medical staff at the psychiatric out-patient clinics, nor the time spent in the various duties of medical personnel in the hospital. However, the figures cited throw some light on differential availability of various grades of staff throughout the Region.

As regards other medical staff employed, only three persons appear to be undertaking part-time service in the mental hospitals of the Region; and in view of the difficulties experienced in filling full-time posts, it would seem that a considerable increase in part-time service might be made.

Nursing Staff Employed.-By recourse to the ward returns previously mentioned, an attempt has been made to give a picture of the disposition of nursing staff by ward on any one day or night. The large proportion of part-time female nurses employed complicates the issue as regards the female wards, and the more so in the absence of data bearing on severity of cases, since the disposition of nurses from day to day presumably depends to some extent upon the type of patients being cared for and the degree of overcrowding, etc. It was apparent from the survey that there was a daily shift system at only one hospital. Elsewhere, full-time nurses work on the wards for 12-hour periods on both day and night duties. The long hours worked per duty, together with the allowance for staff on leave and sick, mean that only about half the nursing strength of the hospital is available for duty at any one time. For this reason, and because at each hospital there are senior members of the nursing staff who do not work on the wards, an evaluation of total nursing staff to patients in residence is certain to be unrealistic.

The grade of nursing staff (whether trained, student, or assistant) was obtained, and with few exceptions each ward is covered by day, in the first instance, by a trained member of staff. At night many wards do not have staff allocated to them but are patrolled at regular intervals by staff from other wards or by a small complement of relief staff. It is possible to review the availability of nursing staff against the background of the four-fold classification

Table IV

MEDICAL STAFF EMPLOYED

\begin{tabular}{|c|c|c|c|c|c|c|c|}
\hline \multicolumn{5}{|c|}{ Grade } & \multirow[b]{2}{*}{$\begin{array}{l}\text { Number of } \\
\text { Patients in } \\
\text { Residence }\end{array}$} & \multirow{2}{*}{$\begin{array}{l}\text { Number of } \\
\text { Patients per } \\
\text { Consultant or } \\
\text { S.H.M.O. }\end{array}$} & \multirow[b]{2}{*}{$\begin{array}{c}\text { Number of } \\
\text { Patients } \\
\text { per Doctor }\end{array}$} \\
\hline $\begin{array}{l}\text { Consultants } \\
\text { and } \\
\text { S.H.M.O.s }\end{array}$ & $\begin{array}{c}\text { Senior } \\
\text { Registrars } \\
\text { and Registrars }\end{array}$ & J.H.M.O.s & Other & Total & & & \\
\hline 35 & 7 & 16 & 10 & 68 & 12,572 & 362 & 186 \\
\hline
\end{tabular}


of wards made in Section 4 above, thus taking into account, to some extent, the type of patient involved. A consolidation of the figures given for each ward by recourse to this classification provides patientstaff ratios at each hospital for trained, student, and other staff respectively. These ratios vary from hospital to hospital within the same class of wards, and the size of each ward has some bearing on the allocation of nursing staff. But the overall ratios for the Region as a whole for each class give reliable estimates of the relative availability of different grades of staff, and such ratios are exhibited in Table $\mathrm{V}$ for male and female wards respectively. Each ratio depicts the number of patients who, on the average, are looked after by a nurse of a given grade during the day-time.

TABLE V

CLASSIFICATION OF WARDS BY TYPE OF PATIENT AND AVAILABILITY OF NURSING STAFF

\begin{tabular}{c|c|c|c|c|c}
\hline \multirow{2}{*}{$\begin{array}{c}\text { Type of } \\
\text { Ward }\end{array}$} & \multicolumn{3}{c}{ Type of Staff } \\
\cline { 3 - 6 } \multicolumn{1}{c|}{} & Trained & Student & $\begin{array}{c}\text { Nursing } \\
\text { Assistants }\end{array}$ & Total \\
\hline \multirow{4}{*}{ Male } & I & 12 & 29 & 83 & 8 \\
& II & 19 & 74 & 124 & 14 \\
& III & 22 & 250 & 65 & 15 \\
& IV & 26 & 667 & 200 & 22 \\
& All & 21 & 128 & 103 & 15 \\
\hline \multirow{4}{*}{ Female } & II & 21 & 38 & 27 & 9 \\
& II & 33 & 57 & 23 & 11 \\
& III & 42 & 204 & 30 & 16 \\
& IV & 60 & 259 & 57 & 26 \\
& All & 39 & 107 & 27 & 15 \\
\hline
\end{tabular}

The disposition of trained staff on both the male and female sides is clearly defined, and for each group of wards there is a greater availability of male trained staff. As would be expected, patientstaff ratios increase throughout from the first group to the fourth group, although a much greater proportion of trained staff is allocated to the last group on the male side. This difference is probably attributable to the fact that some male staff go out to work with the patients, whereas female patients working outside the wards are supervised by catering and laundry staff. On the male side trained staff appear to be allocated to the second and third groups in almost equal proportions, whereas on the female side there is a considerable difference in the degree of allocation between these two groups.

The patient-staff ratios for student nurses increase far more rapidly over the four groups than do the above ratios for trained staff. Male student nurses are allocated almost entirely to the short-stay wards and to the wards with bedridden cases, and in proportion to the number of patients respectively involved they are, of course, mainly allocated to the former group. Female student nurses are similarly dispersed, although a not insignificant proportion is allocated to the third group. The student coverage of the admission units is more satisfactory on the male side, and the converse is true for the other three groups.

The disposition of nursing assistants is not so clearly defined as for the foregoing grades of nursing staff, and presumably their allocation is partially associated with the shortage of student nurses. There is a much greater degree of availability of this grade of female staff than male, and the female distribution is probably more representative of the method of allocation. A large proportion of female nursing assistants is employed on wards in the third group; but relative to the number of patients involved they are allocated in almost equal proportions to the first three groups, with a slight preponderance in the second. The lowest patient-staff ratio for this grade of male staff appears in the third class of wards, and, as for the female side, the highest ratio is in the fourth.

The patient-staff ratios reveal a negligible difference between the male and female wards in total staff coverage for any one group; there is one nurse to fifteen patients for each sex when all wards are considered. The final analysis for nursing staff by grade, irrespective of type of ward, shows that there are almost twice as many male as female trained nurses available per patient and almost four times as many female as male nursing assistants per patient. There are slightly more female students per patient than male.

The foregoing results indicate the disposition of nursing staff available at the time of the survey, taking into account inter-ward differences with respect to patients cared for. They may therefore be used to assess more accurately than hitherto the availability of staff at a particular hospital, but it remains to decide how many staff of different grades should be employed on a ward of a given type. Prerequisite to a judicious decision is a thorough analysis of the nursing problems involved, against the background of the above classification.

Domestic Staff and Ward Orderlies.-There is little domestic staff on the wards and the number of ward orderlies available at each hospital is very small. Work on the wards is almost entirely done by patient labour under supervision of nursing staff. In practice, this means that nurses are likely to become involved in domestic work, since patient labour is commonly unreliable. As the numbers involved are so small it is difficult to obtain a true picture of the disposition of these types of staff, and an analysis by type of ward, as previously given in 
respect of nursing staff, is not satisfactory. However, it may be stated that domestic staff and ward orderlies are mainly allocated to Ward Types I and II on both the male and female sides, there being approximately three times as many members of staff per patient on these wards as on the others. In proportion to the number of patients involved, about three times as many females as males are available at any one time, and very few part-time male domestic staff are employed.

\section{Psychiatric Out-Patient Clinics}

An exhaustive analysis of the work of out-patient clinics was not possible for the reasons given in Section 2, but we may review the turnover of these clinics at an elementary level by recourse to basic administrative data, such as the number of new patients, the total out-patient attendances, and the number of consultant sessions. Such figures were available for 1952 for each mental hospital and each out-patient department in the associated general hospitals.

The medical staffs of the mental hospitals hold clinics at $\mathbf{2 5}$ general hospitals in the Region, and out-patients are also seen at most of the mental hospitals. During 1952, 3,813 consultant sessions were held, at which 6,775 patients attended for the first time during that year, so that on the average two new patients were seen per consultant session, There is, of course, some variation from clinic to clinic about this Regional average in respect of the average number seen per session, the two extremes being 0.3 at one cottage hospital and 5.4 at one of the large general hospitals. The average number of all attendances (new and old) per consultant session is found to be 7.8 for the Region as a whole, although there is considerable variation from clinic to clinic. Broadly speaking, therefore, two new and six old patients are seen at a single session.

\section{Discussion}

It is doubtful whether many participants in public controversy concerning the need for economy realize that one-half of all the persons for whom the Birmingham Regional Hospital Board, like many others, has the responsibility of providing institutional accommodation are mentally deranged or defective. From this survey, several aspects of the problem of appropriate provision of accommodation for the former class of patient are brought into focus, and by an examination of mental hospitals on a ward basis the gravity of the present situation in other respects is more clearly defined. The degree of overcrowding on individual wards has been ascertained and the results reveal a shortage of accommodation which is often underestimated by reliance on a figure for overcrowding in a hospital as a whole. The consequences of such a level of overcrowding are very apparent. They include:

(i) poor facilities for the clinical classification of patients;

(ii) the with-holding of in-patient treatment from potential voluntary patients who would benefit therefrom;

(iii) falling recruitment and high wastage of student nurses.

While it is not intended to underestimate the value of medical supervision where neither treatment nor prevention is the end in view, the blunt truth is that the problem of accommodation is essentially a domestic one. In fact, the problem of appropriate provision for mental patients has much in common with the problem of appropriate provision for the chronic-aged, inasmuch as it is the responsibility of the Health Service to discharge the dual function of:

(a) efficient treatment of remediable cases;

(b) humane hotel-keeping on behalf of the incurable.

On the other hand, it presents difficulties and opportunities peculiar to its forensic implications and to the historical background of the disposal of persons in need of protection or of restraint.

Estimates of the relative proportions of these two classes of patient, $(a)$ and $(b)$ above, are given by the analysis of patients in residence by length of stay. It is probably true to say that on any one day at least 85 per cent, of the total in-patient population are chronic cases in that they are unlikely ever to leave hospital. In terms of costing, this raises the question: can we effect beneficial economies by segregating the remediable where expert services are more readily available and the incurable in equally congenial circumstances without redundant provision of medical personnel at consultant level. It is not intended to discuss here the consequences of an affirmative answer to this question, since they involve consideration of another issue, viz. the practicability and advisability of treating certain types of mental illness in hospitals other than those under review.

Unless new circumstances conspire to reverse or partially eliminate current trends, it is difficult to see how the present very serious situation can be prevented from deteriorating in the immediate future. Not only is the population of England and Wales steadily increasing, but it is, at the same time, ageing, and, since the incidence rates of certain psychoses increase with age, the population of mental hospitals is likely to increase. This survey has shown that 22 per cent. of all male patients and 34 per cent, of all female patients resident at the 
present time in mental hospitals in the Birmingham Region are 65 years of age or over, as compared with 9 per cent. and 12 per cent. respectively in the general population. If we relate the numbers of patients in residence to the total population by sex and agegroup, we find that per 10,000 of the male population there are 34 patients in residence aged between 16 and 64 years inclusive and 70 patients aged 65 years and over. The corresponding rates for females are 36 and 105 . Since we may expect both the proportion of people over 65 years of age and the proportion of females to males in this age-group to increase, it is certain that greater demands on beds will be made during the next two decades unless discharge and death rates increase to the same extent. There appears to be no indication that new treatments will materially increase the discharge rate; and there is every reason for assuming that the death rate will decrease.

However, an examination of other aspects of the current situation, particularly of the incidence of first admissions by sex, age, and diagnosis, will have to be undertaken before making even tentative estimates of future requirements in terms of beds, staffing, and ancillary facilities. This issue will be dealt with in a subsequent contribution. Without the introduction of new incentives, it is also abundantly clear that the difficulties of recruitment and retention of staff, particularly of junior medical staff and of nursing staff, will continue. The shortage of the former might be partially offset by effecting an increase in the numbers of doctors employed part-time. The shortage of nursing staff would appear to be even more serious, and a review of trends over recent years gives some indication of the magnitude of the problem confronting the Mental Health Service. It will suffice to give a few facts:

(i) The number of trained nursing staff has remained fairly constant since 1947, although on the female side this constancy has been maintained by employing more part-time qualified nurses.

(ii) The number of student nurses in training has steadily decreased, and in 1952 was the lowest ever.

(iii) The number qualifying is decreasing, and 40 per cent. of female students and 5 per cent. of the male students leave the Mental Health Service on qualifying.

(iv) The retirement rate among qualified staff is about 5 per cent. per annum.

(v) To offset these reductions larger numbers of nursing assistants are being employed. Such staff are, of course, ineligible for the posts of ward sister or charge nurse, and offer no security for the future.

It would appear, therefore, that it is unlikely that mental hospitals will in future years be able to maintain even the present level of nursing staff if the present trends continue. The high wastage rate of 80 per cent. for student nurses is perhaps the most serious aspect of the present situation. The gross overcrowding on many wards is an important contributory factor and the impact of such conditions upon a young nurse just leaving the preliminary training school is considerable. Another important aspect of student-nurse wastage is that staff shortages exclude the possibility of selective recruitment.

The accommodation available at each hospital for full-time staff, together with the number of quarters occupied on the day of the survey, was obtained separately for each type of staff. It was found that all quarters set aside for medical staff were occupied at most hospitals and that presumably any increase of medical staff would necessitate a re-organization of existing quarters. It would seem that with few exceptions, adequate provision has been made for female nurses, quantitatively speaking, and it is doubtful whether, even if an appreciable increase in the nursing strengths was effected, all the available quarters would be filled. On the other hand, very few of the available quarters for male nurses were unoccupied, and for maintenance and domestic staff there were no vacant quarters at most hospitals either within the hospital buildings or outside. An increase of quarters for male resident staff would probably facilitate recruitment, although it appears that, in view of the long hours spent in the hospital buildings, nurses are likely to prefer their living quarters to be situated elsewhere.

\section{SUMmary}

(1) An examination has been made of several of the problems of providing adequate care and treatment for patients resident in the mental hospitals of the Birmingham Region.

(2) The survey reveals the greater degree of overcrowding at night of the female wards than of the male, and shows that at many hospitals only the admission units and sick wards are not overcrowded.

(3) The analysis of patients in residence shows that:

(a) 34 per cent. of the female and 22 per cent. of the male patients are over 65 years of age, and 0.6 per cent. of the female and 0.4 per cent. of the male patients are under 16 years of age;

(b) one fifth of all patients in residence are voluntary patients:

(c) 85 per cent. of all patients have been in residence for more than one year and 70 per cent. of the male and 72 per cent. of the female patients have been in hospital for more than 3 years; with the exception of two hospitals, more than half the patients at each institution have been in residence for longer than 5 years; 
(d) one-tenth of the male and one-eighth of the female patients are bedridden, and at all hospitals, with one exception, the proportion of female bedridden patients is higher than that of the male patients; one-tenth of the male and almost one-fifth of the female patients are incontinent;

(e) at least half the male patients and at least one-third of the females are kept occupied for some part of the day;

(4) A review of medical staff at present employed shows that few Senior Registrars and Registrars are employed, and that many hospitals have no junior staff; in fact more than half the medical personnel are of consultant or S.H.M.O. grade.

(5) An assessment of nursing staff available has been made, classifying wards according to type of patient; and patient-staff ratios have been calculated for each group. These may be used to examine the extent of nurse coverage of a particular type of ward at any one hospital. The relative values of these ratios also reveal the current use of the available staff in different types of ward.
(6) The consequences of present trends with regard to both patients and staffs are commented upon.

I should like to record my appreciation of the co-operation which I have received from the staffs of the mental hospitals, in particular from the medical superintendents and nursing staffs who were concerned in the extraction of detailed information referable to the patients in residence. My thanks are due to Dr. Raymond Wrighton, one time Research Fellow in this Department, for his invaluable assistance in the collection of data and for his constructive criticism in the compilation of this report. Finally, I wish to express my gratitude to Professor Lancelot Hogben, F.R.S., for his advice at all stages of this survey.

\section{REFERENCES}

Blacker, C. P. (1946). "Neurosis and the Mental Health Services". Oxford University Press, London.

Board of Control: Lunacy and Mental Deficiency (1953). "39th Annual Report, 1952". H.M.S.O., London.

FitzGerald, O. (1953). Brit. med. J., 1, 1,392.

Lancet (1952). 2, 344. (Notes and News-unsigned.)

Ibid. (1953). 2, 176. (Annotation-unsigned.)

lbid. (1953) 2, 715. (Annotation-unsigned.)

lbid. (1953). 2, 715. (Annotation-unsigned.)
lbid. (1953). 2, 927. (Annotation-unsigned.)

Norris, V. (1952). Ibid., 2, 1172.

Petrie, A. A. W. (1953). Brit. med. J., 2, 43

Sandison, R. A., and Spencer, A. M.'(1953). Ibid., 560. 